\title{
Nicotine Attenuates the Ventilatory Response to Hypoxia in the Developing Lamb
}

\author{
JOSEPH MILERAD, ${ }^{1}$ HANS LARSSON,${ }^{2}$ JING LIN,${ }^{3}$ AND HÅKAN W. SUNDELL \\ Department of Pediatrics, Vanderbilt University [J.M., J.L., H.W.S.], Nashville, Tennessee 37232-2585 \\ and Department of Biomedical Engineering, Karolinska Institute [H.L.], Stockholm, Sweden
}

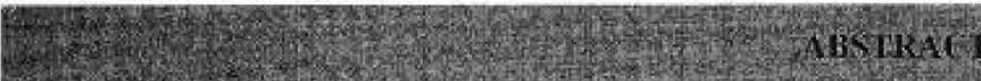

Decreased ability to generate a hyperventilatory response to hypoxemia is believed to be an important mechanism in the pathophysiology of sudden infant death syndrome, and maternal smoking is a leading risk factor. To investigate whether there may be a link between these two observations, we studied five lambs at mean ages of 7, 17, and $27 \mathrm{~d}$ to determine the effects of an i.v. infusion of nicotine $(0.5 \mu \mathrm{g} / \mathrm{kg} / \mathrm{min})$ on ventilation when peripheral chemoreceptor activity was stimulated by hypoxia $\left(0.1 \mathrm{FiO}_{2}\right)$ or briefly inhibited by hyperoxia. Ventilatory measurements were performed using a computer-aided occlusion valve device which permitted breath-by-breath determinations of inspiratory occlusion pressures $\left(\mathrm{P}_{0.1}\right)$ and minute ventilation. Nicotine attenuated the early ventilatory response to hypoxia (min 1,2 , and 3 of the test) by 8,26 , and $37 \%$, respectively, at the age of $7 \mathrm{~d}$ (analysis of variance overall, $p<0.05$ ), by $23 \%$, 23 and $37 \%$ at $17 \mathrm{~d}(p=\mathrm{NS})$ and by 40,45 , and $37 \%$ at $27 \mathrm{~d}(p$ $<0.05$ ). The decrease in ventilation in response to hyperoxia during the control study without nicotine was 18,35 , and $34 \%$ at 7,17 , and $27 \mathrm{~d}$, respectively. Nicotine caused a greater decrease in the response: 31,45 , and $46 \%$, respectively, ( $p<0.05$ at 27 d). The paradoxical effects of nicotine, attenuation of the ventilatory response to hypoxia and augmentation of the response to
\end{abstract}

hyperoxia, suggest that nicotine altered peripheral chemoreceptor oxygen sensitivity and most likely also affected central processing of the chemoreceptor input. It is hypothesized that the association between parental smoking and sudden infant death syndrome is related to the adverse effects of nicotine on central control of breathing. (Pediatr Res 37: 652-660, 1995)

CB, carotid body

Abbreviations

DA, dopamine

EtCO ${ }_{2}$, end-tidal $\mathrm{CO}_{2}$

$\mathbf{P}_{\mathbf{0 . 1}}$, inspiratory occlusion pressure

$\mathbf{R R}$, respiratory rate

SIDS, sudden infant death syndrome

$\mathbf{T}_{\mathbf{1}}$, inspiratory time

$\mathbf{T}_{\mathbf{r}}$, respiratory cycle duration

$\dot{\mathbf{V}}_{\mathbf{I}}$, inspiratory minute ventilation

$\mathbf{V}_{\mathbf{T}}$, tidal volume

$\mathbf{V}_{\mathbf{T}} / \mathbf{T}_{\mathbf{I}}$, mean inspiratory flow

ANOVA, analysis of variance

REG, regression

$\mathrm{FiO}_{2}$, fraction of inspired air
A substantial number of infants who die of SIDS have been reported to have brain stem gliosis (1) and elevated hypoxanthine levels in the vitreous humor (2), findings suggestive of repeated hypoxemic episodes before death. These observations, together with reports of altered neurotransmitter content

Received July 13, 1994; accepted January 2, 1995.

Correspondence and reprint requests: Håkan W. Sundell, M.D., Vanderbilt University Medical School, Room U-1212, MCN, Nashville, TN 37232-2585.

Supported by grants from the National Institute of Health (HD22721, HD28916 and HL14214) and by the Swedish Medical Research Council (J.M.).

These results were presented in part at the annual meeting of the American Pediatric Society and the Society for Pediatric Research 1992 and at the State of the Art Conference on the Sudden Infant Death Syndrome arranged by the Swedish Medical Research Council in 1992.

${ }^{1}$ Current address: Department of Pediatrics, Karolinska Hospital, Stockholm, Sweden

${ }^{2}$ Current address: Department of Biomedical Engineering, Karolinska Institute, Stockholm, Sweden.

${ }^{3}$ Current address: New York University Medical Center, Department of Pediatrics, New York, New York 10016. of the carotid bodies (3), support the hypothesis that a decreased ability to generate a forceful hyperventilatory response to hypoxemia is an important factor in the etiology of SIDS.

Of the various environmental risk factors associated with SIDS, maternal smoking, both in pregnancy and during neonatal life, is one of the most predictive (4-6). The incidence of SIDS in children of smoking women increases in proportion to tobacco consumption; smoking more than 20 cigarettes a day increases the relative risk 5 -fold $(4,7)$. There are also indications that the time of death coincides with actual nicotine exposure as evidenced by high levels of nicotine metabolites in pericardial fluid in almost half of infants dying of SIDS in one series (8).

The observations of nicotine exposure as a major risk factor and a deficient hypoxic defense as a possible mechanism prompted us to investigate whether nicotine adversely affects the postnatal development of the ventilatory responsiveness to hypoxia. 
The risk of SIDS from parental smoking has usually been attributed to the well-known adverse effects on fetal and infant well-being, i.e. low birth weight and frequent upper airway infection $(9,10)$. In contrast, our hypothesis was that smoking directly compromises the hypoxic defense and that this effect results from the effects of nicotine on neurotransmission. Because nicotine has powerful stimulatory effects on CB activity (11) and chronic prenatal exposure has been shown to produce long-term alterations in synaptic transmission in both rat fetuses and rat pups $(12,13)$, it seemed likely that this substance has the potential to alter peripheral chemoreceptor oxygen sensitivity as well as the central processing of chemoreceptor input $(14,15)$. The study was carried out in chronically instrumented lambs which were studied sequentially during the first $4 \mathrm{wk}$ after birth. The ventilatory effects of an i.v. infusion of nicotine were determined when peripheral chemoreceptor activity was stimulated by hypoxia or inhibited by hyperoxia.

\section{METHODS}

Subjects. Five lambs of mixed breed were studied at an age of $6.6 \pm 0.9,17.4 \pm 2.9$, and $27.4 \pm 5.3 \mathrm{~d}$ (mean $\pm \mathrm{SD}$ ). Body weight of the lambs at the time of the studies was $6.0 \pm 0.7$, $9.0 \pm 1.0$, and $12.2 \pm 1.2 \mathrm{~kg}$, respectively.

Lamb preparation. The animals were instrumented at the age of 2-4 d, after they had documented good health and vigor. Catheters were inserted in the cranial tibial artery and lateral saphenous vein and a tracheostomy was performed after lidocaine infiltration anesthesia complemented by i.v. ketamine. After the tracheostomy, continuity between lower and upper parts of the trachea was reestablished through a 4-cm piece of endotracheal tube (no. 4-6, Portex, Inc., Keene, NH), allowing the lamb to breathe normally through the upper airway, when not being studied. Antibiotics (gentamicin $4 \mathrm{mg} / \mathrm{kg}$ and carbenicillin $100 \mathrm{mg} / \mathrm{kg}$ ) were given daily from the time of instrumentation until the last study. A postoperative 48-h recovery period was allowed before the first study was performed. The lambs were housed with the ewe and nursed ad libitum. The research protocol was approved by the Vanderbilt University Animal Care Committee.

Equipment. The technique used for breath-by-breath measurements of $\mathrm{P}_{0.1}, \dot{\mathrm{V}}_{\mathrm{I}}, \mathrm{V}_{\mathrm{T}}, \mathrm{RR}, \mathrm{V}_{\mathrm{T}} / \mathrm{T}_{\mathrm{Y}}$, and $\mathrm{EtCO}_{2}$ has previously been validated in this lamb model and has been found to have minimal or no effects on ventilation and breathing pattern (16).

The tracheostomy tube of the lamb was connected to a pneumatic occlusion valve assembly, acting as a combined inspiratory and occlusion valve. The occlusion valve was positioned on the inspiratory side. An expiratory circuit containing a one-way valve served the purpose of maintaining functional residual capacity in the absence of laryngeal expiratory airflow braking was located on the expiratory side. The expiratory valve was a flap valve with an opening pressure of $0.5 \mathrm{~cm} \mathrm{H}_{2} \mathrm{O}$ and an approximately linear resistance of $2.2 \mathrm{~cm}$ $\mathrm{H}_{2} \mathrm{O} \cdot \mathrm{L}^{-1} \cdot \mathrm{s}$ in the $0.1-0.25 \mathrm{~L} / \mathrm{s}$ interval. These characteristics produced a pressure peak at the beginning of expiration of 2.5-3 $\mathrm{cm} \mathrm{H}_{2} \mathrm{O}$ followed by a gradual pressure decline to a lowest pressure of $0.5 \mathrm{~cm} \mathrm{H}_{2} \mathrm{O}$ at end expiration.
Inspiratory airflow was determined by a HP model 21071B size no. 1 pneumotachograph (Hewlett-Packard, Waltham, MA) positioned outside the occlusion valve assembly on the inspiratory side of the occlusion valve. The pneumotachograph was calibrated with air. Therefore, the $\mathrm{V}_{\mathrm{T}}$ readings during hyperoxia were approximately $10 \%$ too high, because the viscosity of pure oxygen is higher than that of air. Airway pressure was measured by means of a catheter inserted into the trachea through a connector in the $\mathrm{T}$ joint. The differential pressure of the HP pneumotachograph, the tracheal pressure, and the pressure indicating occlusion valve opening were measured with three Validyne MP 45-1 differential pressure transducers (Validyne Engineering Corp., Northridge, CA). Gas for $\mathrm{EtCO}_{2}$ measurements was sampled at a rate of $3 \mathrm{ml} / \mathrm{s}$ from the $\mathrm{T}$ joint, and the $\mathrm{CO}_{2}$ concentration was analyzed in a Beckman LB2 infrared capnograph (Beckman Instruments Inc., Anaheim, CA).

Data processing. The analog signals of airway pressure, inspiratory airflow, a square-wave signal indicating valve opening, and $\mathrm{EtCO}_{2}$ were sampled in real time, converted to digital form at $200 \mathrm{~Hz}$ in a 12-bit $\mathrm{A} / \mathrm{D}$ converter card, and stored on the disk of an AT-compatible personal computer (NEC Portable Powermate, NEC Technology, Boxborough, MA) on a breath-by-breath basis. In addition to digital storage, all signals were continuously graphically displayed on an eight-channel Hewlett Packard 8800S cardiovascular recording system. $\dot{V}_{\mathrm{I}}, \mathrm{V}_{\mathrm{T}}, \mathrm{T}_{\mathrm{I}}, \mathrm{T}_{\mathrm{T}}, \mathrm{RR}, \mathrm{V}_{\mathrm{T}} / \mathrm{T}_{\mathrm{I}} \cdot \mathrm{P}_{0.1}$ and $\mathrm{EtCO}_{2}$ were computed from the flow, pressure, and $\mathrm{CO}_{2}$ recordings, respectively. These data were corrected for the increased flow produced by $\mathrm{CO}_{2}$ sampling $(3 \mathrm{ml} / \mathrm{s})$ and for the flow $(3 \mathrm{ml} / \mathrm{s})$ needed to generate the subatmospheric pressure required to keep the membrane of the occlusion valve assembly in place.

Computations. $\mathrm{P}_{0.1}$ is conventionally defined as the negative airway pressure at $100 \mathrm{~ms}$ after beginning of an occluded inspiration. In more general terms, this pressure drop can be expressed as the slope of airway pressure plotted versus time, with airway pressure on the ordinate and time on the abscissa. If the unit of time on the $x$ axis is set to $100 \mathrm{~ms}$, the slope of the plotted curve will be numerically equivalent to $P_{0.1}$. This more general mathematical definition, i.e. the decrease in airway pressure per $100 \mathrm{~ms}$, was used in this study to calculate $P_{0.1}$.

During the study, the negative valve opening pressure was set to exceed by approximately $0.5 \mathrm{~cm} \mathrm{H}_{2} \mathrm{O}$ the minimum negative inspiratory pressure of unoccluded breaths. The point of valve opening, the lowest inspiratory pressure reached during each breath, was detected, and linear regression equation of airway pressure versus time was computed. This technique obviated the need for a fixed-time occlusion, which during high respiratory rates would lead to a significant airway obstruction. Detailed information regarding the principles of this analysis is available elsewhere (17).

Procedures. The lambs were studied only if their temperature was normal, $39-40^{\circ} \mathrm{C}$, and if they did not show signs of infection or ill health. Before each investigation, the tracheal prosthesis was removed and replaced by a cuffed endotracheal tube of appropriate size. To facilitate this procedure, the lamb 
was lightly sedated with $0.1 \mathrm{mg} / \mathrm{kg}$ i.v. diazepam. The animal was then allowed to adapt to the tube for approximately $30 \mathrm{~min}$ before it was connected to the recording equipment. Room temperature during the study was kept at $21-24^{\circ} \mathrm{C}$.

Test protocol. Each lamb served as its own control. The test sequence consisted of a control study with measurements of resting ventilation, ventilatory response to hyperoxia, and a hypoxic challenge. The entire test sequence as outlined above was repeated $15 \mathrm{~min}$ after starting a continuous i.v. infusion of $0.5 \mu \mathrm{g} / \mathrm{kg} / \mathrm{min}$ of nicotine bitartrate in saline. There were at least $5 \mathrm{~min}$ between hyperoxia tests, at least $15 \mathrm{~min}$ between hyperoxia tests, and at least $1.5 \mathrm{~h}$ between hypoxia tests.

Measurements of resting ventilation during normoxia. A representative 5-min recording of quiet breathing (approximately 200 breaths) was sampled during baseline room air conditions.

Ventilatory response to hyperoxia. During resting ventilation, the inspired gas was abruptly switched from ambient air to $100 \% \mathrm{O}_{2}$. An interval of $20 \mathrm{~s}$ before the switch was used as a baseline period, and the first $10 \mathrm{~s}$ (or first five breaths, whichever came first) after the switch were used as the test period. If the 10-s period ended between two breaths, the complete next breath was included in the analysis. The decrease in minute ventilation (expressed as percent of baseline) was used as an index of chemoreceptor response. Two tests, 5 min apart, were performed at each age.

Ventilatory response to hypoxia. During resting ventilation, inspired gas was abruptly switched from ambient air to $10 \% \mathrm{O}_{2}$ in nitrogen which had been warmed to room temperature and humidified. The last minute before the switch was used as a baseline period. The hypoxic challenge was maintained for 10 min. No attempt was made to maintain isocapnia. An arterial blood sample for determination of $\mathrm{PO}_{2}$ was obtained during each minute of hypoxia.

Statistics. Two-way ANOVA repeated measures design was used to compare the nicotine and control tests. The null hypothesis was rejected for $p<0.05$. Duncan's multiple range test was then used for significance of differences at the $p<$ 0.05 level. Linear REG was used to evaluate the effect of increasing postnatal age on the response patterns. Spearman correlation test or linear REG were used to test how respiratory variables correlated. In all types of analysis, the animals served as their own controls. Results are reported as mean $\pm \mathrm{SD}$.

\section{RESULTS}

Developmental changes in resting ventilation and effects of nicotine. Resting minute ventilation during the control study decreased significantly with postnatal age from a mean of 409 $\mathrm{ml} \cdot \mathrm{kg}^{-1} \cdot \mathrm{min}^{-1}$ at $7 \mathrm{~d}$ to $253 \mathrm{ml} / \mathrm{kg} / \mathrm{min}$ at $25 \mathrm{~d}$ (REG, linear correlation $r=-0.77, p<0.001$ ) (Table 1). The mean increase in $\dot{\mathrm{V}}_{\mathrm{I}}$ during nicotine infusion was $20 \%$ at $7 \mathrm{~d}$ of age (NS, $p<0.1), 13 \%$ at $17 \mathrm{~d}$ of age $(p<0.05)$ and $27 \%(p<$ $0.01)$ at $27 \mathrm{~d}$. The increase in $\dot{V}_{I}$ was produced largely by an increase in respiratory rate. Nicotine infusion increased resting ventilation in every animal although the increase varied considerably, particularly in the youngest animals, which may explain why a statistically significant difference was not attained at the age of $7 \mathrm{~d}$. As a reflection of the nicotine-induced increase in ventilation, a statistically significant reduction of $\mathrm{EtCO}_{2}$ was observed at $27 \mathrm{~d}$.

Nicotine increased mean inspiratory flow $\left(\mathrm{V}_{\mathrm{T}} / \mathrm{T}_{\mathrm{I}}\right)$ at all ages, and this difference was statistically significant at $27 \mathrm{~d}$ (Table 1). Nicotine increased $P_{0.1}$ by a mean of 79 and $19 \%$, at 7 and $17 \mathrm{~d}$, respectively (Table 1). As was the case with $\dot{\mathrm{V}}_{\mathrm{I}}$, the rise in $\mathrm{P}_{0.1}$ also varied markedly in the youngest lambs, the consequence being that the mean increase was not statistically significant.

Effects of postnatal age, hypoxia, and nicotine on effective inspiratory impedance. To assess whether suppositional nicotine- or hypoxia-induced changes in respiratory mechanics had affected the obtained results, the inspiratory driving force relative to the ventilatory output was estimated using determination of effective inspiratory impedance, $\mathrm{P}_{0.1} /\left(\mathrm{V}_{\mathrm{T}} / \mathrm{T}_{\mathrm{I}}\right)$ ratio. During the first minute of hypoxia, mean effective inspiratory impedance increased by approximately $22 \%$ across all age groups (NS). Nicotine had no statistically significant effects on the $\mathrm{P}_{0.1} /\left(\mathrm{V}_{\mathrm{T}} / \mathrm{T}_{\mathrm{I}}\right)$ ratio. No significant effects of increasing postnatal age were observed during either normoxia or hypoxia (Table 2).

Developmental changes in response to hyperoxia and effects of nicotine. The ventilatory response to hyperoxia was expressed as percent change in $V_{I}$ from the baseline period. As illustrated in Figure 1, the inhibitory effect of hyperoxia on ventilation increased with postnatal age both in the control studies and during nicotine infusions. The regression equation for control studies was $y=-18.2-0.58 x(p<0.05)$ and for

Table 1. Effect of nicotine on resting ventilation in five lambs studied repeatedly

\begin{tabular}{|c|c|c|c|c|c|c|c|c|}
\hline & $\begin{array}{l}\text { Age } \\
\text { (d) }\end{array}$ & $\begin{array}{l}\text { Body weight } \\
(\mathrm{kg})\end{array}$ & $\begin{array}{c}\dot{\mathrm{V}}_{\mathrm{I}} \\
\left(\mathrm{ml} \cdot \mathrm{min}^{-1} \cdot \mathrm{kg}^{-1}\right)\end{array}$ & $\begin{array}{c}\mathrm{V}_{\mathrm{T}} \\
\left(\mathrm{ml} \cdot \mathrm{kg}^{-1}\right)\end{array}$ & $\begin{array}{c}\mathrm{RR} \\
(\mathrm{bpm}) \\
\end{array}$ & $\begin{array}{c}\mathrm{V}_{\mathrm{T}} / \mathrm{T}_{\mathrm{I}} \\
\left(\mathrm{ml} \cdot \mathrm{s}^{-1} \cdot \mathrm{kg}^{-1}\right)\end{array}$ & $\begin{array}{c}\mathrm{P}_{0.1} \\
\left(\mathrm{~cm} \mathrm{H} \mathrm{H}_{2} \mathrm{O}\right) \\
\end{array}$ & $\begin{array}{c}\mathrm{EtCO}_{2} \\
(\%) \\
\end{array}$ \\
\hline Control & & & $409.3 \pm 64.6$ & $10 \pm 1.9$ & $41.2 \pm 4.9$ & $20.4 \pm 4.4$ & $2.9 \pm 1.4$ & $5.9 \pm 0.3$ \\
\hline Nicotine & 7 & $6.0 \pm 0.7$ & $492.0 \pm 133.2$ & $9.4 \pm 1.2$ & $51.0 \pm 9.3$ & $24.5 \pm 7.5$ & $5.2 \pm 2.1$ & $5.4 \pm 0.4$ \\
\hline Control & & & $324.1 \pm 49.3$ & $8.6 \pm 2.0$ & $39.0 \pm 10.7$ & $17.2 \pm 5.4$ & $4.2 \pm 1.9$ & $5.9 \pm 0.3$ \\
\hline Nicotine & 17 & $9.0 \pm 1.0$ & $366.6 \pm 30.1^{*}$ & $8.2 \pm 2.0$ & $45.8 \pm 9.2$ & $19.6 \pm 2.4$ & $5.0 \pm 2.0$ & $5.8 \pm 0.3$ \\
\hline Control & & & $252.6 \pm 47.6$ & $7.8 \pm 1.2$ & $30.8 \pm 4.2$ & $14.7 \pm 4.3$ & $3.6 \pm 0.9$ & $6.1 \pm 0.3$ \\
\hline Nicotine & 27 & $12.2 \pm 1.2$ & $319.7 \pm 27.1 \dagger$ & $7.7 \pm 1.0$ & $38.2 \pm 5.2$ & $\begin{array}{r}19.5 \\
\pm 4.3^{*}\end{array}$ & $3.6 \pm 0.8$ & $5.5 \pm 0.2 \dagger$ \\
\hline
\end{tabular}

Values are means $\pm \mathrm{SD}$.

* Statistically significant difference between the studies at $p<0.05$.

$\dagger$ Statistically significant difference between the studies at $p<0.01$. 
Table 2. Effect of nicotine on $P_{0.1} /\left(V_{T} / T_{I}\right.$ ratio $)$ ratio $\left(\mathrm{cm} \mathrm{H}_{2} \mathrm{O} \cdot \mathrm{sec} / \mathrm{ml}\right)$ during normoxia and hypoxia

\begin{tabular}{|c|c|c|c|c|c|c|}
\hline & \multicolumn{2}{|c|}{$7 \mathrm{~d}$} & \multicolumn{2}{|c|}{$17 \mathrm{~d}$} & \multicolumn{2}{|c|}{$27 \mathrm{~d}$} \\
\hline & Normoxia & Hypoxia & Normoxia & Hypoxia & Normoxia & Hypoxia \\
\hline Control & $0.027 \pm 0.008$ & $0.035 \pm 0.010$ & $0.027 \pm 0.008$ & $0.034 \pm 0.005$ & $0.024 \pm 0.005$ & $0.030 \pm 0.010$ \\
\hline Nicotine & $0.030 \pm 0.011$ & $0.036 \pm 0.013$ & $0.028 \pm 0.008$ & $0.035 \pm 0.011$ & $0.021 \pm 0.006$ & $0.028 \pm 0.009$ \\
\hline
\end{tabular}

Values are mean \pm SD of five lambs studied repeatedly.

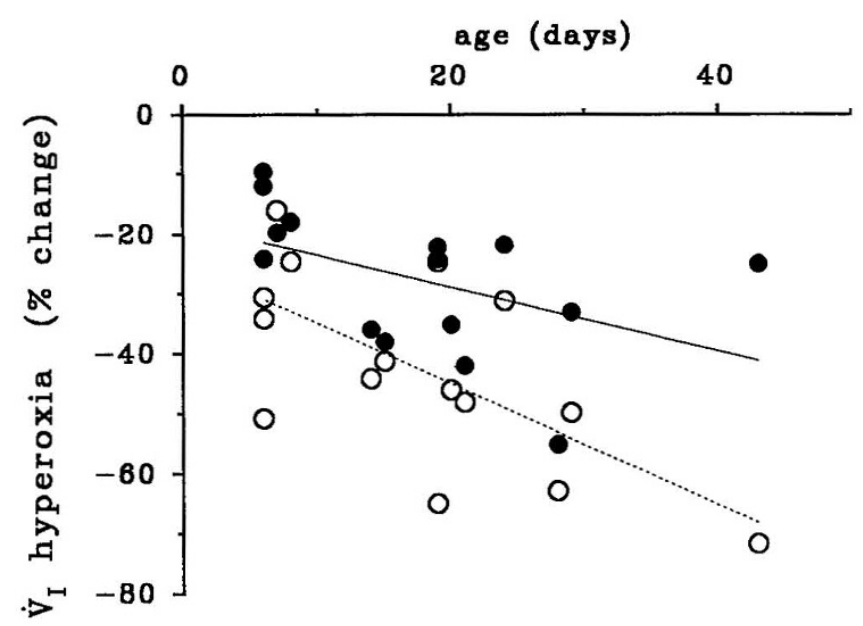

Figure 1. The inhibitory effect on ventilation in response to hyperoxia $(1.0$ $\mathrm{FiO}_{2}$ ) as a function of postnatal age in five lambs studied on three occasions during control conditions (closed circles) and during a nicotine infusion (open circles). The response is expressed as percent decrease in $\dot{\mathrm{V}}_{\mathrm{I}}$ from baseline. REG equation for control tests: $y=-18.19-0.54 x(p<0.05)$. REG equation for nicotine tests: $y=-25.1-0.88 x(p<0.01)$.

nicotine infusions $y=-25.1-0.88 x(p<0.01)$. The decrease in $\dot{\mathrm{V}}_{\mathrm{I}}$ after the switch to $100 \% \mathrm{O}_{2}$ was largely related to the decrease in respiratory rate. No significant decrease in $\mathrm{P}_{0.1}$ was observed during the hyperoxic challenge.

The mean response to hyperoxia during the control study was an $18 \%$ decrease in $\dot{\mathrm{V}}_{\mathrm{I}}$ at $7 \mathrm{~d}$, a $35 \%$ decrease at $17 \mathrm{~d}$ and a $34 \%$ decrease at $27 \mathrm{~d}$ (Fig. 2). Nicotine augmented the inhibitory effect on ventilation in response to hyperoxia in all lambs except in one animal during the first test performed at 5 $\mathrm{d}$ of age. The stronger response during nicotine infusions was statistically significant only at $27 \mathrm{~d}(p<0.05)$ (Fig. 2). The wide range of the individual responses may have contributed to the lack of statistical significance at 7 and $17 \mathrm{~d}$.

To determine to what extent the increase in resting ventilation paralleled the stimulation of the peripheral chemoreceptors, the nicotine-induced augmentation of the response to hyperoxia was compared with the increase in resting ventilation in each individual lamb. The relationship between the increase in resting ventilation and the inhibition of ventilation by hyperoxia was not statistically significant $(\beta=0.1, p>0.1$ linear correlation $r=0.34$ ).

Developmental changes in response to hypoxia and effects of nicotine. The increase in ventilation during the first minute of hypoxia plotted versus postnatal age varied considerably between individual lambs (Fig. 3). The ventilatory response to hypoxia during the control studies increased significantly with increasing postnatal age (REG equation: $y=56.3+1.59 x$, $p<0.05)$. In contrast to the control studies, ventilatory re-

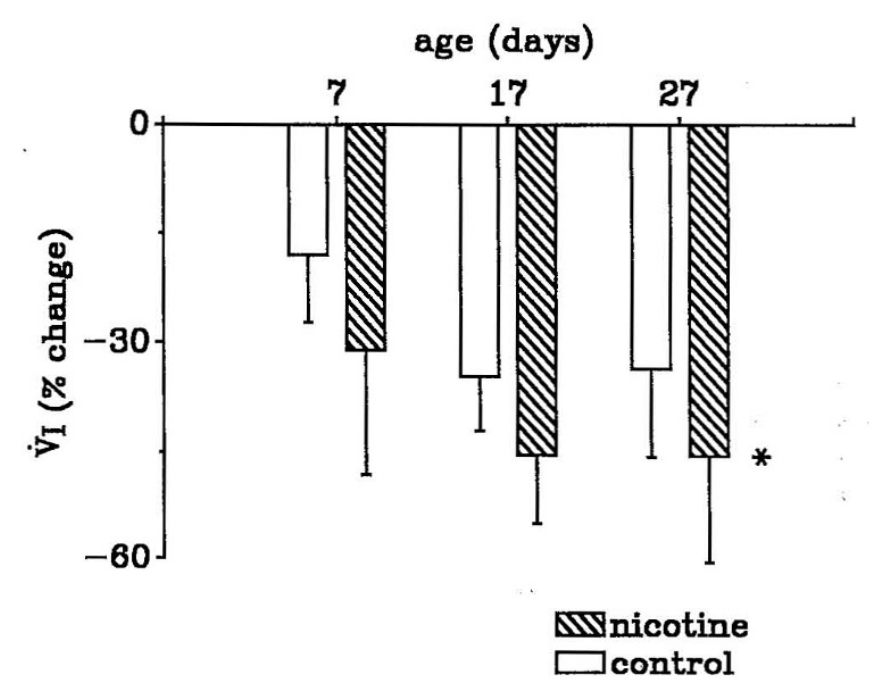

Figure 2. Effect of nicotine on the ventilatory response to hyperoxia in five lambs studied on three occasions. The response is expressed as percent decrease in $\dot{V}_{\mathrm{I}}$ from baseline. Values are mean $\pm \mathrm{SD}$. ${ }^{*}$ Statistically significant difference between the tests at $27 \mathrm{~d}(p<0.05)$.

sponse to hypoxia during nicotine infusions did not change significantly as the lambs matured (REG equation: $y=52.6+$ $0.43 x$, NS) (Fig. 3)

The early ventilatory response to hypoxia $\left(\dot{V}_{I}\right.$ during the first 3 min of the test) was attenuated by nicotine in all lambs at 7 $\mathrm{d}$, in four of five lambs at $17 \mathrm{~d}$, and in all lambs at $27 \mathrm{~d}$. At the age of $7 \mathrm{~d}$, the mean response decreased by 8,26 , and $37 \%$ during the first, second, and third minute of the test, respec-

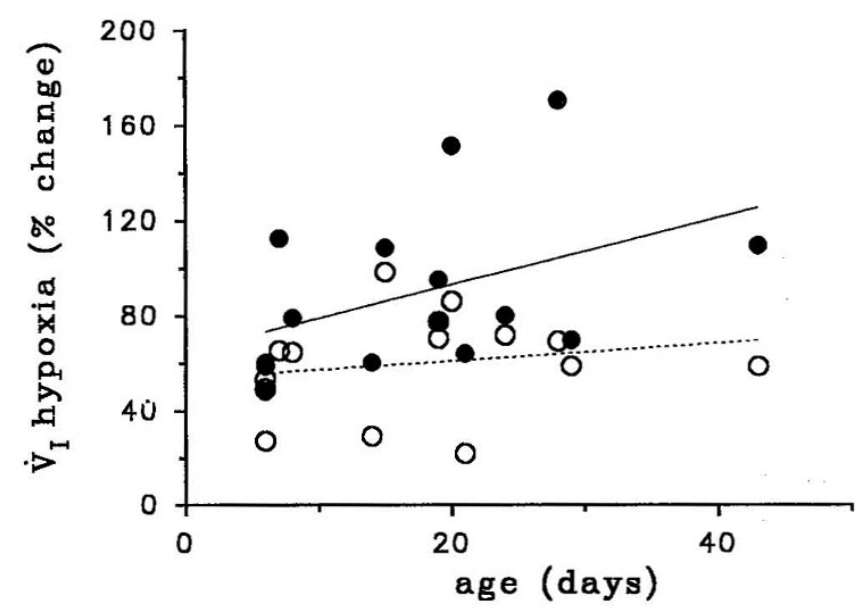

Figure 3. The ventilatory response to hypoxia $\left(0.1 \mathrm{FiO}_{2}\right)$ as a function of postnatal age in five lambs studied on three occasions during control conditions (closed circles) and during a nicotine infusion (open circles). Each symbol represents the percent increase in $\dot{V}_{1}$ from baseline during the first minute of the test. Regression equation for control tests: $y=56.3+1.59 x(p<0.05)$. REG equation for nicotine tests: $y=52.6+0.43 x(p<0.01)$. 

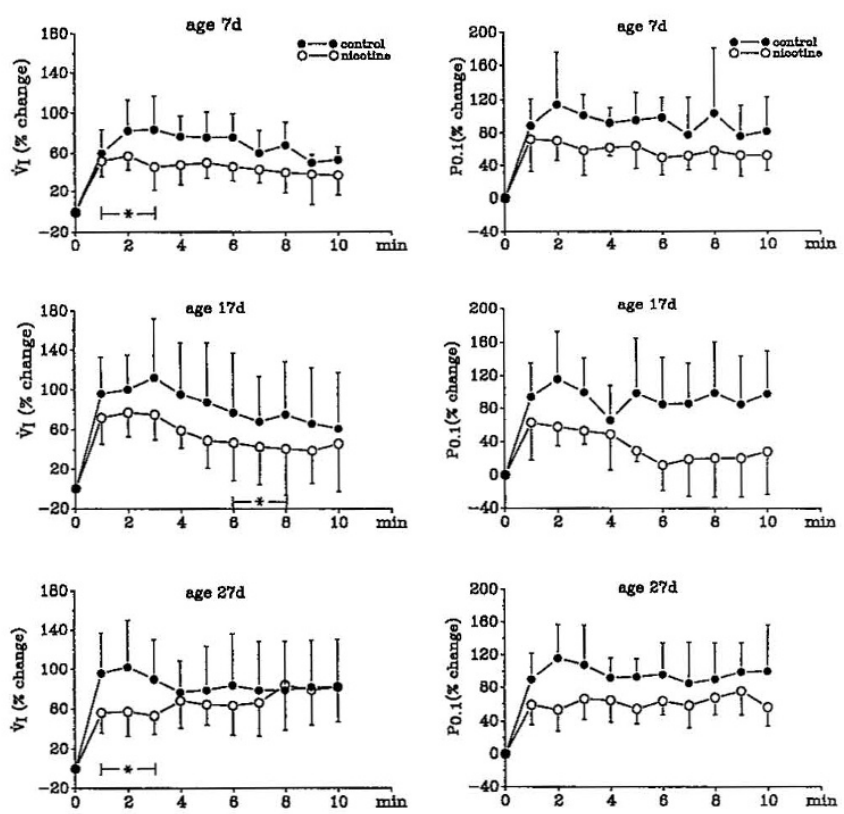

Figure 4. Effect of nicotine on $\dot{\mathrm{V}}_{\mathrm{I}}$ and $\mathrm{P}_{0.1}$ during acute hypoxia $\left(0.1 \mathrm{FiO}_{2}\right)$ in five lambs studied on three occasions. The response is expressed as percent increase from baseline. Values are mean $\pm \mathrm{SD}$. * Statistically significant difference between the studies $(p<0.05)$.

tively (ANOVA overall, $p<0.05$ ) (Fig. 4). At $17 \mathrm{~d}$, the mean response decreased by 23,23 , and $37 \%$ (NS). At $27 \mathrm{~d}$, the mean observed decrease was 40, 45, and 37\% (ANOVA overall, $p<$ 0.05 ). When the first minute of the response to hypoxia was compared among the three age groups, the nicotine-induced attenuation was most pronounced at the age of $27 \mathrm{~d}$ (ANOVA, $p<0.05)$.

Attenuation of the early ventilatory response to hypoxia after nicotine was not only a reflection of an increased resting ventilation leading to lower relative response. The ventilatory response to hypoxia also decreased in absolute terms by $13 \pm$ $24 \mathrm{ml} \cdot \mathrm{kg}^{-1} \cdot \mathrm{min}^{-1}$ at $17 \mathrm{~d}$ and $68 \pm 11 \mathrm{ml} \cdot \mathrm{kg}^{-1} \cdot \mathrm{min}^{-1}$ at $27 \mathrm{~d}$. At $7 \mathrm{~d}$, the response increased by $70 \pm 68$ $\mathrm{ml} \cdot \mathrm{kg}^{-1} \cdot \min ^{-1}$.

Analysis of $V_{T}$ and $R R$ showed that the hypoxia induced increase in $\dot{V}_{I}$ was a result of increased $V_{T}$ as well as increased RR. The response patterns were quite similar to the $\dot{V}_{I}$ response to hypoxia, although the difference between control and nicotine tests were less obvious. The increase in RR during hypoxia during the first $3 \mathrm{~min}$ was lower during the nicotine tests by $20 \pm 4 \%$ at $7 \mathrm{~d}(p<0.05), 14 \pm 29 \%$ at $17 \mathrm{~d}(\mathrm{NS})$ and $13 \pm$ $41 \%$ at $27 \mathrm{~d}(\mathrm{NS})$. The increase in $\mathrm{V}_{\mathrm{T}}$ was lower during the nicotine tests by $10 \pm 25 \%$ at $7 \mathrm{~d}(\mathrm{NS}), 5 \pm 17 \%$ at $17 \mathrm{~d}$ (NS), and $12 \pm 19 \%$ at $27 \mathrm{~d}$ (NS). When the three age groups were compared, nicotine-induced attenuation of the early response with regard to $\mathrm{V}_{\mathrm{T}}$ was most pronounced at $27 \mathrm{~d}$ (ANOVA, $p<0.01$ ).

Nicotine attenuated the increase in $\mathrm{V}_{\mathrm{T}} / \mathrm{T}_{\mathrm{I}}$ during the early response by $39 \pm 48 \%$ at $7 \mathrm{~d}(\mathrm{NS}), 19 \pm 32 \%$ at $17 \mathrm{~d}(\mathrm{NS})$, and $30 \pm 18 \%$ at $27 \mathrm{~d}(p<0.05)$. When the three age groups were compared by ANOVA, nicotine-induced attenuation of the early response with regard to $\mathrm{V}_{\mathrm{T}} / \mathrm{T}_{\mathrm{I}}$ was most pronounced at 27 d (ANOVA, $p<0.001$ ).

Nicotine attenuated $\mathrm{P}_{0.1}$ during the early response to hypoxia in four out of five lambs in every age group. The mean decrease of the early response ranged from 31 to $67 \%$, but this difference in $\mathrm{P}_{0.1}$ did not reach statistical significance due to a large individual variation among the lambs (Fig. 4).

Analysis of control and nicotine tests with regard to the late response was performed on $\min 6,7$, and 8 of the hypoxia challenge, because the nicotine effect was most apparent in this interval. A statistically significant difference was observed only at the age of $17 \mathrm{~d}$, when nicotine attenuated the $\dot{\mathrm{V}}_{\mathrm{I}}$ response by 73,67 , and 79\%, respectively (ANOVA overall, $p<0.05$ ) (Fig. 4). This attenuation in ventilatory response was paralleled by a decrease in $\mathrm{P}_{0.1}$ which, however, was not statistically significant (Fig. 4).

Changes in $\mathrm{Pao}_{2}$ during hypoxia. Nicotine did not significantly alter mean $\mathrm{PaO}_{2}$ during the baseline period before the hypoxia test at any age (Table 3). $\mathrm{PaO}_{2}$ levels between min 1 and 10 of the hypoxia tests were averaged for each lamb, and control tests were compared with nicotine tests. There was no significant influence by nicotine on $\mathrm{Po}_{2}$ during hypoxia at any age (Table 3).

Comparison of ventilatory response to hyperoxia and hypoxia. The inhibitory effect on ventilation induced by hyperoxia was plotted against the stimulatory effect on ventilation induced during the first minute of hypoxia and is presented in Figure 5. There was a statistically significant linear relationship between the response to hypoxia and the response to hyperoxia in the control studies (REG, $p<0.001$ ). No such relationship was found during the nicotine studies.

\section{DISCUSSION}

The main finding of this study was that nicotine, which is known to increase ventilation and to stimulate carotid body discharge, depressed the ventilatory response to hypoxia in the developing lamb. Paradoxically, although the ventilatory response to hypoxia was attenuated by nicotine, the ventilatory response to hyperoxia was augmented, indicating an enhanced tonic activity of the peripheral chemoreceptors. These opposing effects of nicotine raise the speculation that stimulation of

Table 3. Effect of nicotine on $\mathrm{PaO}_{2}(\mathrm{kPa})$ measured before and during hypoxia tests

\begin{tabular}{|c|c|c|c|c|c|c|}
\hline & \multicolumn{2}{|c|}{$7 \mathrm{~d}$} & \multicolumn{2}{|c|}{$17 \mathrm{~d}$} & \multicolumn{2}{|c|}{$27 \mathrm{~d}$} \\
\hline & Baseline & Hypoxia & Baseline & Hypoxia & Baseline & Hypoxia \\
\hline Control & $12.0 \pm 1.2$ & $4.2 \pm 0.5$ & $11.6 \pm 1.2$ & $4.8 \pm 0.5$ & $12.1 \pm 1.8$ & $4.9 \pm 0.5$ \\
\hline Nicotine & $12.4 \pm 1.0$ & $4.3 \pm 0.5$ & $12.4 \pm 1.2$ & $4.7 \pm 0.5$ & $12.2 \pm 1.5$ & $4.8 \pm 0.7$ \\
\hline
\end{tabular}

Values are mean $\pm \mathrm{SD}$ of five lambs studied repeatedly. 

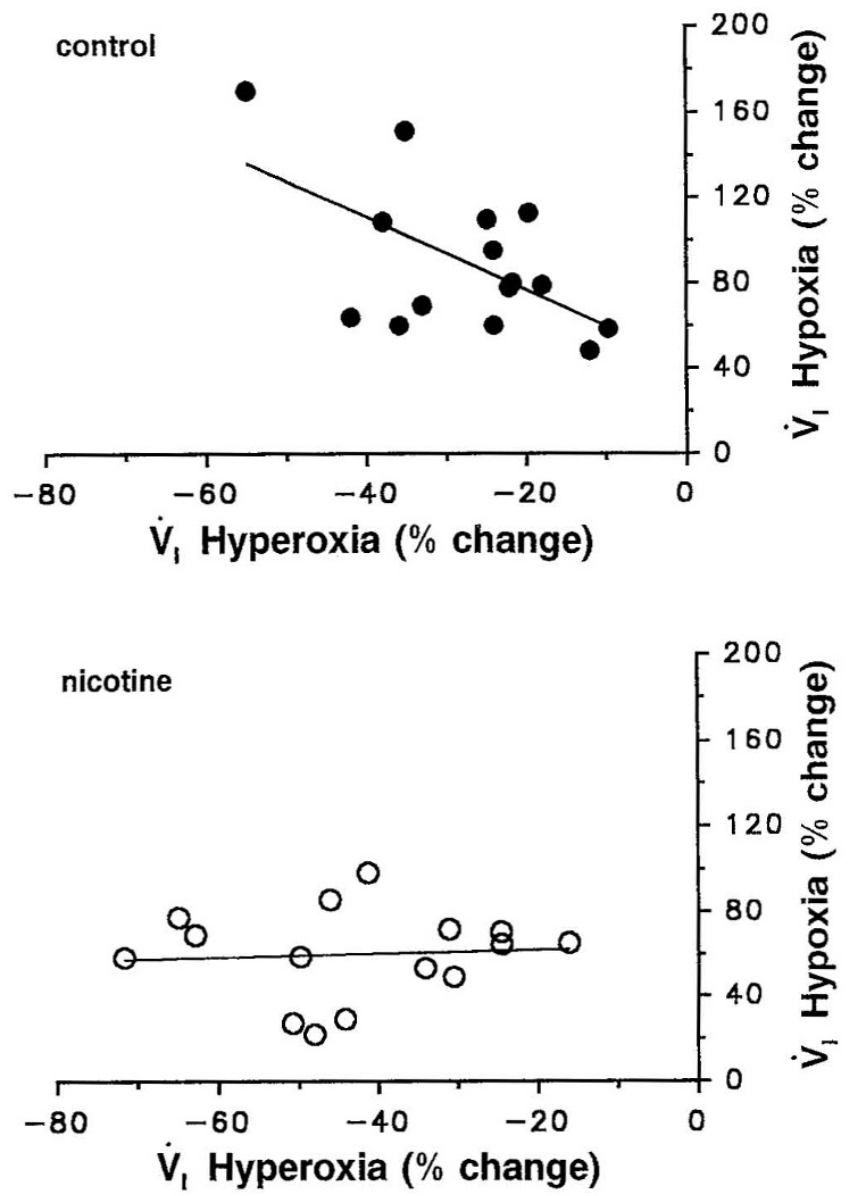

Figure 5. The ventilatory response to hypoxia $\left(0.1 \mathrm{FiO}_{2}\right)$ as a function of the ventilatory response to hyperoxia $\left(1.0 \mathrm{FiO}_{2}\right)$ in five lambs studied on three occasions during control conditions and during an infusion of nicotine. The response to hypoxia is expressed as percent increase $\dot{V}_{I}$ from baseline during the first minute of the test. The response to hyperoxia is expressed as percent decrease an $\dot{\mathrm{V}}_{\mathrm{I}}$ from baseline. REG equation for control tests: $y=20.3+2.31 x$ $(p<0.001)$. REG equation for tests during a nicotine infusion: $y=63.9-$ $0.09 x(\mathrm{NS})$.

the peripheral chemoreceptors by hypoxemia as opposed to inhibition of their tonic activity by hyperoxia are mediated, in part, by separate mechanisms. However, as discussed below, the disparate effects of nicotine on the ventilatory response to hyperoxia and hypoxia cannot be fully explained unless the possibility is taken into account that the central processing of the chemoreceptor input has been altered by this drug.

Inasmuch as nicotinic receptors are abundantly present in the CNS at neuromuscular junctions and in peripheral synaptic nerve terminals (18), the physiologic effects of this drug are complex and also to a large extent dependent on the dosage and the route of administration $(19,20)$. We used a constant infusion rate of $0.5 \mu \mathrm{g} \cdot \mathrm{kg}^{-1} \cdot \mathrm{min}^{-1}$. A dose of $1.5-2$ $\mu \mathrm{g} \cdot \mathrm{kg}^{-1} \cdot \min ^{-1}$ has been used in acute experiments to simulate cigarette-smoking in adults (21). This i.v. dose yields plasma nicotine concentrations of $20-30 \mathrm{ng} / \mathrm{ml}$ (22), that is approximately equivalent to smoking one pack of cigarettes a day. Plasma concentrations of infants moderately exposed to passive smoking are around $2 \mathrm{ng} / \mathrm{ml}$ (23). By extrapolating dose-plasma concentration ratios from pharmacokinetic studies in adults (21), we elected to use one-fourth of the adult dose, i.e. $0.5 \mu \mathrm{g} \cdot \mathrm{kg}^{-1} \cdot \min ^{-1}$ as a dose likely to simulate heavy passive smoking exposure. This dose is also lower than the usual 2-6 $\mathrm{mg} \cdot \mathrm{kg}^{-1} \cdot \mathrm{d}^{-1}$ dose used in chronic studies to simulate nicotine exposure to the developing fetus $(18,24)$. The lower of these chronic dosages has not been associated with toxic effects or neuronal damage but has been shown to have significant effects on catecholamine release and turnover (13).

Because adrenergic nerve terminals are the prime target for nicotine, its most apparent effect is activation of the sympathetic nervous system. This general sympathetic activation, which includes a rise in metabolic rate, may, in part, account for the increase in resting ventilation as seen in this and previous studies (11). However, the excitatory effects of nicotine on respiration are also related to stimulation of medullary chemoreceptors, vagal afferents, and peripheral chemoreceptors $(11,25,26)$. These more specific effects on respiration may explain why the stimulatory effects in this study were more apparent when the animals were older. The effects of central and peripheral chemoreceptor stimulation are generally believed to increase with postnatal age (27).

The powerful stimulatory effect of nicotine on $\mathrm{CB}$ efferent discharge has been documented through direct recordings from the sinus nerve in adult cats (11). In fact, nicotine, along with its agonist lobeline, have been used extensively as pharmacologic CB stimulants $(11,28)$. Because direct measurements of peripheral chemoreceptor discharge are not possible in intact subjects, we used the hyperoxia test to estimate the effect of nicotine on CB activity, or more specifically on its tonic activity during normoxia (29-31). Although this tonic activity usually parallels oxygen sensitivity in terms of rise in activity during hypoxemia, the correlation between these two responses may change when the $\mathrm{CB}$ are pharmacologically stimulated by agents known to interfere with neurotransmission, e.g. nicotine. In other words, a drug-induced increase in tonic activity may not necessarily imply that the sensitivity to decreases in arterial oxygen tension also is enhanced and vice versa. This hypothesis, that the tonic activity and oxygen sensitivity may not be equivalent under certain conditions, could explain the dissociation between the response to hypoxia and the response to hyperoxia during nicotine infusion. During the control tests, the magnitude of the response to hyperoxia followed closely the response to hypoxia. By contrast, no such relationship could be identified during the nicotine infusion tests.

Nicotine augmented the inhibition of ventilation in response to hyperoxia in all lambs except in one test performed at $6 \mathrm{~d}$ of age. The augmentation of the hyperoxic response after nicotine increased significantly with increasing postnatal age, i.e. the difference between control and nicotine tests increased as the lambs became older. The reason for the more pronounced effect of nicotine in the older animals is unclear, since little is known about how postnatal development influences the effects of nicotine on synaptic transmission. A possible explanation for the observed age effect might be that nicotine-induced stimulation of $\mathrm{CB}$ discharge is counteracted by a more marked nicotine-induced release of DA from the CB type I glomus cell terminals (32) in the youngest lambs. In the CB, DA acts as an 
inhibitory neuromodulator on chemoreception $(33,34)$. Increased release or intracarotid DA infusion has been shown to attenuate oxygen sensitivity (33). In the rat, an age-related decrease in CB DA levels has been shown to parallel the postnatal increase in hyperoxic response (35). In analogy, nicotine-induced DA release could be more pronounced in the youngest age group that would counteract direct stimulation of CB discharge by nicotine (36).

Results of the hypoxia tests obtained during control conditions confirm and complement previous studies on this subject $(29,31,37)$. The ventilatory response to hypoxia increased progressively with increasing postnatal age, and a significant correlation with the response to hyperoxia was observed. In contrast to the control tests, the early response to hypoxia during nicotine infusion was of similar magnitude in all age groups. The response was attenuated compared with the control tests and did not correlate to the response to hyperoxia.

Inasmuch as the postnatal increase in ventilation during hypoxia as well as the postnatal rise in hyperoxic inhibition of breathing are ultimately determined by central integration of the chemoreceptor input, nicotine may have changed the response either by altering CB oxygen sensitivity or the central processing of carotid input, or both.

In the adult cat, Mulligan and Lahiri (38) have shown that nicotine augments $\mathrm{CB}$ discharge through a direct stimulation via nicotine receptors. This stimulatory effect could be abolished by mecamylamine, a ganglionic-type nicotine receptor blocker. However, the rise in $\mathrm{CB}$ activity during hypoxia was not altered by mecamylamine, i.e. the hypoxic stimulation was of the same magnitude when nicotine was given alone or after mecamylamine pretreatment. It can thus be inferred from these observations that stimulation of nicotinic receptors does not play a major role in mediating the ventilatory response to hypoxia in the cat (38). Because nicotine has powerful stimulatory effects on peripheral chemoreceptor tonic discharge, but it does not enhance the rise in peripheral chemoreceptor discharge during hypoxia, these two effects may be mediated through separate mechanisms. If so, the peripheral chemoreceptors may have a "set point" and a "gain" in analogy to that being attributed to the central chemoreceptors. This concept is further illustrated in Figure 5 that shows a highly significant correlation in the control studies between the magnitude of the inhibitory effect on ventilation induced by hyperoxia (set point) and the stimulatory effect induced by hypoxia (gain). Such a relationship was not observed during the nicotine studies, suggesting that the tentative relationship between "set point" and "gain" had been altered.

While the observations of Mulligan and Lahiri (38) may explain why the hypoxic response was not augmented by nicotine, they cannot explain an attenuated response. As previously mentioned, the stimulatory effects of nicotine on the $\mathrm{CB}$ may be modulated by the increase in DA release. During hypoxia, the nicotinic receptors within the chemosensory tissue play a major role in modulating catecholamine release in the cat. Blocking of these receptors in vitro has been shown to decrease DA release by almost 50\% (28). Consequently, the lack of an increased ventilatory response to hypoxia after nicotine administration may be related to an enhanced DA release resulting in a moderate attenuation of the response.

An alternative explanation for why nicotine decreased the ventilatory response to hypoxia may be that nicotine enhanced DA release in the brainstem which altered the central integration of chemoreceptor input. There is a wide variety of evidence demonstrating that nicotine has potent effects on DA release in dopaminergic neurons in the CNS. One significant clinical observation is that smoking has protective effects on the development of Parkinson's disease (39). Nicotine-induced activation of presynaptic nicotinic receptors at the dopaminergic nerve terminals in striatal and mesolimbic regions has been shown to stimulate release of DA $(40,41)$ and to increase the number of postsynaptic dopaminergic binding sites (42), suggesting that DA plays a role in mediating the central nicotine effects.

Drug-induced dissociation between peripheral stimulation and central inhibition has been demonstrated previously in maturing rabbits by Schramm and Grunstein (43), who found that $\mathrm{NaCN}$-enhanced peripheral chemoreceptor input during hypoxia was centrally modulated to produce ventilatory depression (43). The evidence for the role of DA in mediating this paradoxical effect was provided by Goiny et al. (44) who demonstrated a decrease in phrenic nerve activity coinciding with an increase in DA release in nucleus tractus solitarii, an area generally assumed to be involved in the integration of $\mathrm{CB}$ output. Further support for a DA-mediated central inhibitory mechanism was provided by Bonora and Gautier (45) who showed that administration of the DA agonist apomorphine has a marked depressive effect on the central ventilatory response to hypoxia in the CB-denervated conscious cat. It can be inferred from these studies that, if dopaminergic mechanisms play a major role in modulating the response to hypoxia, these effects can theoretically be mimicked by nicotine administration.

To determine which mechanism most likely was responsible for blunting of the hypoxia response is, however, not possible on the basis of the present study. The purpose of this investigation was not to differentiate between central and peripheral effects of nicotine administration. Future investigations specifically devised to address this issue are needed.

Inasmuch as it could not be excluded that a nicotine influence on respiratory mechanics might account for some of the observed changes in $\dot{\mathrm{V}}_{\mathrm{I}}$, the $\mathrm{P}_{0.1} /\left(\mathrm{V}_{\mathrm{T}} / \mathrm{T}_{\mathrm{I}}\right)$ ratio (46) was determined on a breath-by-breath basis during normoxia and during hypoxia. The rationale for this approach was that any significant changes in respiratory mechanics may alter the relationship between the driving force (i.e. $\mathrm{P}_{0.1}$ ) and the ventilatory output. No statistically significant effect of nicotine on $\mathrm{P}_{0.1} /$ $\left(\mathrm{V}_{\mathrm{T}} / \mathrm{T}_{\mathrm{I}}\right)$ ratio was found.

Clinical implications. Because a large number of observations suggest that hypoxemia is likely to play a role in SIDS (2), any given factor that will impair the defense mechanisms to hypoxemia may increase the probability of a fatal event. Results of the present study suggest that nicotine, by altering the ventilatory response to hypoxia, may be a potential detrimental factor. 
Our hypothesis, that nicotine increases the risk of SIDS by altering chemoreceptor oxygen sensitivity, is supported by observations that some victims of SIDS have markedly increased DA and noradrenaline concentrations in their CB (3). Nicotine has clearly been shown to increase both DA and noradrenaline release at glomus cells terminals (32) which could account for the elevated catecholamine concentrations. If this effect is related to nicotine exposure specifically, one would expect that only a subset of infants who die of SIDS would exhibit these findings.

In the clinical scenario, attenuation of the ventilatory response to hypoxia may be important when inspiratory resistance is increased. The decreased ventilatory response to hypoxia observed in this study was accompanied by a decrease in central inspiratory drive, as measured by $\mathrm{V}_{\mathrm{T}} / \mathrm{T}_{\mathrm{I}}$. This suggests that the decrease in the ventilatory response was due to an inhibition in respiratory center output, a finding with potential significance in a situation where an increased inspiratory effort is required, such as during airway obstruction.

The divergent effects of an acute nicotine infusion, increased tonic activity of the peripheral chemoreceptors and attenuation of the response to hypoxia, may also have another potential implication. Reflex interaction between chemoreceptor and baroreceptor stimulation during apnea reflex stimulation, e.g. from laryngeal stimulation, may lead to severe bradycardia. An augmentation of this reflex interaction has been shown in infants who subsequently died of SIDS (47). Similar augmentation of reflex bradycardia has experimentally been produced by stimulation of the chemoreceptors with nicotine (15).

Summary. This study in young lambs has shown that an acute infusion of nicotine stimulates resting ventilation, augments the ventilatory response to hyperoxia, and attenuates the ventilatory response to hypoxia. The results indicate that the tonic activity of the peripheral chemoreceptors are enhanced by nicotine. The reduced ventilatory response to hypoxia may be a result from altered chemoreceptor oxygen sensitivity or an influence on the central processing of the chemoreceptor input, or both. The nicotine-induced attenuated ventilatory response to hypoxia may have clinical implications, because a decreased ability to generate a hyperventilatory response to hypoxemia is believed to be an important mechanism in the pathophysiology of SIDS. Based on these results, it is hypothesized that the association between parental smoking and SIDS is related to the adverse effects of nicotine on the central control of breathing.

Acknowledgments. The authors thank Patricia Minton, R.N., Stanley Poole, M.S., and Rao Gaddipati, M.S., for their skilled technical assistance, and Donna Staed for typing the manuscript.

\section{REFERENCES}

1. Naeye RL, Olsson JM, Combs JW 1989 New brain stem and bone marrow abnormalities in victims of sudden infant death syndrome. J Perinatol 9:180-183

2. Rognum TO, Saugstad OD 1991 Hypoxanthine levels in vitreous humor: evidence of hypoxia in most infants who died of sudden infant death syndrome. Pediatrics $87: 306-310$
3. Perrin DG, Cutz E, Becker LE, Bryan AC, Madapallimatum A, Sole MJ 1984 Sudden infant death syndrome: increased carotid-body dopamine and noradrenaline content. Lancet 2:535-537

4. Mitchell EA, Scragg R, Stewart AW, Becroft DM, Taylor BJ, Ford RP, Hassall IB Barry DM, Allen EM, Roberts AP 1991 Results from the first year of the New Zealand cot death study. NZ Med J 104:71-76

5. Haglund B, Cnattingius S 1990 Cigarette smoking as a risk factor for sudden infant death syndrome: a population-based study. Am J Public Health 80:29-32

6. Hoffman HJ, Damus K, Hillman L, Krongrad E 1988 Risk factors for SIDS. Results of the National Institute of Child Health and Human Development SIDS Cooperative Epidemiological Study. Ann NY Acad Sci 533:13-30

7. Rintahaka PJ, Hirvonen J 1986 The epidemiology of sudden infant death syndrome in Finland in 1969-1980. Forensic Sci Int 30:219-233

8. Milerad J, Sundell H 1993 Nicotine exposure and the risk of SIDS (review). Acta Peadiatr 82(suppl 389):70-72

9. Taylor B, Wadsworth J 1987 Maternal smoking during pregnancy and lower respiratory tract illness in early life. Arch Dis Child 62:786-791

10. Cnattingius S, Haglund B, Meirik O 1988 Cigarette smoking as a risk factor for late fetal and early neonatal death. Br Med 297:258-261

11. Zapata P, Zuazo A, Llados F 1976 Respiratory and circulatory reflexes induced by nicotine injections: role of carotid body chemoreceptors. Arch Int Pharmacodyn Ther 219:128-139

12. Navarro HA, Seidler FJ, Whitmore WL, Slotkin TA 1988 Prenatal exposure to nicotine via maternal infusions: effects on development of catecholamine systems. J Pharmacol Exp Ther 244:940-944

13. Navarro HA, Seidler FJ, Eylers JP, Baker FE, Dobbins SS, Lappi SE, Slotkin TA 1989 Effects of prenatal nicotine exposure on development of central and peripheral cholinergic neurotransmitter systems. Evidence for cholinergic trophic influences in developing brain. J Pharmacol Exp Ther 251:894-900

14. Navarro HA, Mills E, Seidler FJ, Baker FE, Lappi SE, Tayyeb MI, Spencer JR, Slotkin TA 1990 Prenatal nicotine exposure impairs beta-adrenergic function: persistent chronotropic subsensitivity despite recovery from deficits in receptor binding. Brain Res Bull 25:233-237

15. Matsumoto S, Nagao T, Ibi A, Nakajima T 1979 Effects of chemoreceptor stimulating agents on reflex bradycardia. Arch Int Pharmacodyn Ther 239:296-307

16. Milerad J, Jing L, Larsson H, Sundell H 1992 Breath by breath determination of inspiratory occlusion pressure in young lambs. Pediatr Res 31:362A (abstr)

17. Larsson H, Hellstrom LG, Linnarsson D 1993 Breath-by-breath determination of inspiratory occlusion pressure. Clin Physiol 13:133-142

18. Grenhoff J, Svensson TH 1989 Pharmacology of nicotine. Br J Addict 84:477-492

19. Benowitz NL, Jacob P, Denaro C, Jenkins R 1991 Stable isotope studies of nicotine kinetics and bioavailability. Clin Pharmacol Ther 49:270-277

20. Jacob P, Benowitz NL, Shulgin AT 1988 Recent studies of nicotine metabolism in humans. Pharmacol Biochem Behav 30:249-253

21. Benowitz NL, Jacob P, Jones RT, Rosenberg J 1982 Interindividual variability in the metabolism and cardiovascular effects of nicotine in man. J Pharmacol Exp Ther 221:368-372

22. Benowitz NL, Kuyt F, Jacob P 1982 Circadian blood nicotine concentrations during cigarette smoking. Clin Pharmacol Ther 32:758-764

23. Luck W, Nau H 1985 Nicotine and cotinine concentrations in serum and urine of infants exposed via passive smoking or milk from smoking mothers. J Pediatr 107:816-820

24. Slotkin TA, Orband Miller L, Queen KL, Whitmore WL, Seidler FJ 1987 Effects of prenatal nicotine exposure on biochemical development of rat brain regions: maternal drug infusions via osmotic minipumps. J Pharmacol Exp Ther 240:602-611

25. Lauweryns JM, Cokelaere M, Deleersynder M, Liebens M 1977 Intrapulmonary neuro-epithelial bodies in newborn rabbits. Influence of hypoxia, hyperoxia, hypercapnia, nicotine, reserpine, L-DOPA and 5-HTP. Cell Tissue Res 182:425-440

26. Dev NB, Loeschcke HH 1979 A cholinergic mechanism involved in the respiratory chemosensitivity of the medulla oblongata in the cat. Pflugers Arch 379:29-36

27. Lagercrantz H, Milerad J, Walker D 1991 Control of ventilation in the neonate. In: Crystal RG, West JB, Barnes PJ, Cherniack NS, Weibel ER (eds) The Lung: Scientific Foundations. Raven Press, New York, pp 1711-1722.

28. Dinger B, Gonzalez C, Yoshizaki K, Fidone S 1985 Localization and function of cat carotid body nicotinic receptors. Brain Res 339:295-304

29. Sladek M, Parker RA, Grogaard JB, Sundell HW 1993 Long-lasting effect of prolonged hypoxemia after birth on the immediate ventilatory response to changes in arterial partial pressure of oxygen in young lambs. Pediatr Res 34:821-828

30. Girard F, Lacaisse A, Dejours P 1960 Le stimulus $\mathrm{O} 2$ ventilatoire à la période néonatale chez l'homme. J Physiol (Paris) 52:108-109

31. Bureau MA, Begin R 1982 Postnatal maturation of the respiratory response to $\mathrm{O}_{2}$ in awake newborn lambs. J Appl Physiol 52:428-433

32. Gomez Nino A, Dinger B, Gonzalez C, Fidone SJ 1990 Differential stimulus coupling to dopamine and norepinephrine stores in rabbit carotid body type I cells. Brain Res 525:160-164

33. Llados F, Zapata P 1978 Effects of dopamine analogues and antagonists on carotid body chemosensors in situ. J Physiol (Lond) 274:487-499

34. Zapata P, Zuazo A 1980 Respiratory effects of dopamine-induced inhibition of chemosensory inflow. Respir Physiol 40:79-92

35. Hertzberg T, Hellstrom S, Lagercrantz H, Pequignot JM 1990 Development of the arterial chemoreflex and turnover of carotid body catecholamines in the newborn rat. J Physiol (Lond) 425:211-225

36. Dawes GS, Hanson MA, Holman RB, McCooke HB 1984 Concentrations of catecholamines and their metabolites in carotid bodies of fetal and new-born lambs. J Physiol (Lond) 346:97P 
37. Bureau MA, Zinman R, Foulon P, Begin R 1984 Diphasic ventilatory response to hypoxia in newborn lambs. J Appl Physiol 56:84-90

38. Mulligan E, Lahiri S 1987 Cat carotid body chemoreceptor responses before and after nicotine receptor blockade with $\alpha$-bungarotoxin. J Auton Nerv Syst 18:25-31

39. Rajput AH, Offord KP, Beard CM, Kurland LT 1987 A case-control study of smoking habits, dementia, and other illnesses in idiopathic Parkinson's disease. Neurology $37: 226-232$

40. Clarke PB 1990 Mesolimbic dopamine activation - the key to nicotine reinforcement? Ciba Found Symp 152:153-162

41. Fung YK, Lau YS 1989 Effect of nicotine pretreatment on striatal dopaminergic system in rats. Pharmacol Biochem Behav 32:221-226

42. Fung YK, Lau YS 1986 Acute effect of nicotine on the striatal dopaminergic system in the rat. J Pharm Pharmacol 38:920-922
43. Schramm CM, Grunstein MM 1987 Respiratory influence of peripheral chemoreceptor stimulation in maturing rabbits. J Appl Physiol 63:1671-1680

44. Goiny M, Lagercrantz H, Srinivasan M, Ungerstedt U, Yamamoto Y 1991 Hypoxiamediated in vivo release of dopamine in nucleus tractus solitarii of rabbits. J Appl Physiol 70:2395-2400

45. Bonora M, Gautier H 1988 Influence of dopamine and norepinephrine on the central ventilatory response to hypoxia in conscious cats. Respir Physiol 71:11-24

46. Sorli J, Grassino A, Lorange G, Milic-Emili J 1978 Control of breathing in patients with chronic obstructive lung disease. Clin Sci Mol Med 54:295-304

47. Wennergren G, Hertzberg T, Milerad J, Bjure J, Lagercrantz H 1989 Hypoxia reinforces laryngeal reflex bradycardia in infants. Acta Paediatr Scand 78:11-17 